\title{
The Right to Sight
}

\section{Nepal BP}

\author{
Chief Editor
}

Kathmandu University Medical Journal

World health organization (WHO) and International agency for the prevention of blindness (IAPB) along with local Governmental and Non- Governmental partners lunched a global initiative for elimination of avoidable blindness in the late 1990s with an aim to eliminate avoidable blindness by the year 2020. World sight day is observed on the second Thursday of October to highlight the plight of people with visual impairment and blindness every year. WHO estimates that 285 million people are visually impaired, 246 million have low vision and 39 million are blind: $80 \%$ percent of the blindness is preventable and $90 \%$ of them live in the developing countries. ${ }^{1}$ Globally, uncorrected refractive errors are the main cause of visual impairment and cataract is the leading cause of blindness. ${ }^{1} \mathrm{~A}$ population based study conducted for people above 30 years of age in central India found that the age standardized prevalence of visual impairment and blindness was $17 \%$ and $0.5 \%$ based on the presenting visual acuity. ${ }^{2}$ This study also showed that the most frequent cause of visual impairment and blindness were refractive errors and cataract $(75 \%)$ respectively.

Nepal conducted population based blindness survey in 1980/1981. The prevalence of blindness in that survey was $0.84 \%$. The causes of blindness were cataract (66.8\%) followed by corneal scars (8.4\%), glaucoma (3.2\%), trachoma (2.4\%) and posterior segment diseases (13.9\%). ${ }^{3}$ Prevalence of refractive errors could not be estimated at that study as visual acuity was recorded with pin hole only. Prevention of blindness program was launched in Nepal following the survey leading to establishment of eye hospitals and training of ophthalmologists and ophthalmic assistants. However, most of the hospitals are located in Kathmandu and accessible areas in plains bordering India. As a result, most of the people receiving eye service are either people from around cities and towns in Nepal or Non-Nepalese. This did not help to reduce visual impairment and blindness to a desirable level in Nepal even though lots of national and international resources were invested towards that end. Studies on ocular morbidity in school children in Kathmandu showed that the prevalence of refractive errors were found from 8.1-11.9 percent. ${ }^{4,5}$

Nepal lunched Vision 2020 Program in the year 1999 with Apex Body for Eye Health at the Ministry of Health and Population. A midterm review of Vision 2020 Nepal was done in 2010 which found that basic eye care facilities were hardly available beyond District head quarters and there were very limited facilities to address uncorrected refractive errors. The review recommended that Government of Nepal should take ownership of eye care and integrate eye care into general health services. ${ }^{6}$ Rapid assessment of avoidable blindness (RAAB) in Nepal was done for people over the age of 50 from 2008 to 2010 and age, sex specific population data from International Database (IDB) were used for the year 2011. ${ }^{7}$ The study showed that the prevalence of blindness due to cataract was reduced only by $21 \%$; and that of corneal scar doubled, glaucoma increased by one third and posterior segment increased by $22 \%$ over the last 30 years in spite of enormous expansion of infrastructure, equipment and human resources for eye care during that period. However, the prevalence of blindness due to Trachoma reduced by $75 \%$ during the same period. As this was not a population based survey, the actual prevalence of visual impairment in children from refractive error could not be ascertained. This study also concludes that there is no integration of eye care services with general health services, provide limited coverage of remote rural areas, emphasize on financial sustainability of eye care service centers rather that focus on reduction of avoidable blindness, majority (64\%) of cataract operations are carried out for foreign nationals and eye care services in Nepal are driven by NGOs with little involvement of Government of Nepal.

The story of eye health services in Nepal is one of failure in the midst of successes. Nepal, now, has thriving state of the art eye hospitals and are well known in South East Asia for providing quality and quantity eye health services not only to the people of Nepal but also to large number of patients coming from India, Bhutan and Bangladesh. Yet, poor Nepalese people living beyond main cities and towns of the country are yet to benefit from the development of eye services in their own country. The Government of Nepal is squarely to be blamed for this. They do not have a clear cut eye health policy, eye health services are not integrated with general health services and the delivery of eye health services is left entirely to Non Governmental 
Organizations (NGOs) who have their own interests and are mainly occupied with being self sufficient and make a name for themselves.

The success story in near elimination of Trachoma from Nepal is because of the government involvement. The government of Nepal established Trachoma Control Program and targeted it to the endemic area. The government now needs to pay special attention to correction of refractive errors in children which is the main cause of visual impairment and target cataract surgery beyond cities and towns which is the main cause of blindness in this country. The best way to do it is probably by integrating eye health services to general health services.

It is high time the Government of Nepal take responsibility for its own people's Right to Sight.

\section{REFERENCES}

1. Pascolini D, Mariotti SP. Global estimates of visual impairment: 2010. Br. J Ophthalmol. 2012;96 (5):614-8.

2. Nangia V, Jonas JB, Gupta R, Khare A, Sinha A. Visual impairment and blindness in Central India: the Central India Eye and Medical Study. Acta Ophthalmol. 2012 Jun 8. doi: 10.1111/j.1755-3768.2012.02447.x. [Epub ahead of print]

3. Brilliant GE, Pokhrel RP, Grasset NC. The epidemiology of blindness in Nepal: Report of the 1981 Nepal Blindness Survey. Chelsea, USA: The Seva Foundation, 1988.

4. Nepal BP, Koirala S, Adhikari S, Sharma AK. Ocular morbidity in school children in Kathmandu. Br J Ophthalmol. 2003; 87(5): 531-4.

5. Shrestha RK, Joshi MR, Ghising R, Rizyal A. Ocular morbidity among children attending Government and private schools of Kathmandu Valley. J Nepal Med Assoc. 2011; 51(184): 182-8.

6. World Health Association. Prevention of Blindness and Deafness News [Internet]. WHO; Jun 2011. Available from: http://www.who.int/blindness/ NEWSLETTERJUNE.pdf

7. Sapkota YD. The Epidemiology of Blindness in Nepal: 2012. Kathmandu: Nepal Netra Jyoti Sangh; 2012. 